Research Paper:

\title{
Immunomodulatory Impacts of Bulbs Extracts From Five Allium Species on IFN- $\gamma$, IL-4, and IL-17 Cytokines
}

\author{
Tayebeh Radjabian $^{12^{*}}$ (D), Zahra Hosseinpur Yektaei ${ }^{1}$ (D), Mohammad Mehdi Naghizadeh ${ }^{1,3}$ (D), Tooba Ghazanfari ${ }^{1}$ (D)
}

1. Immunoregulation Research Center, Shahed University, Tehran, Iran.

2. Department of Biology, Faculty of Basic Sciences, Shahed University, Tehran, Iran.

3. Non-Communicable Diseases Research Center, Fasa University of Medical Sciences, Fasa, Iran

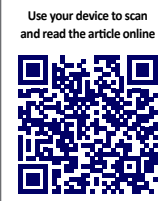

Citation Radjabian T, Hosseinpur Yektaei Z, Naghizadeh MM, Ghazanfari T. Immunomodulatory Impacts of Bulbs Extracts From Five Allium Species on IFN- $\gamma$, IL-4, and IL-17 Cytokines. Immunoregulation. 2022; 4(2):91-100. http://dx.doi. org/10.32598/Immunoregulation.4.2.4

doi http://dx.doi.org/10.32598/Immunoregulation.4.2.4

Article info:

Received: 06 Oct 2021

Accepted: 20 Oct 2021

Available Online: 01 Jan 2022

Keywords:

Allium species, Bulb extract, IFN- $\gamma$, IL-4, IL-17

\begin{abstract}
A B S T RA C T
Background: Nowadays, the impacts of medicinal plants on immune-related diseases are one of the main pharmacological approaches. Thus, here, the modulatory potential of some Allium species on $\mathrm{T}$ helper cell cytokines were investigated.

Materials and Methods: The different concentrations of aqueous extract of the aged bulbs of five Allium species were prepared. Lymphocytes were then isolated and cultured in the presence of the bulb extracts. The amounts of IFN- $\gamma$, IL-4 and IL- 17 were assessed using ELISA.

Results: The results demonstrated that $A$. sativum bulbs extract increased IFN- $\gamma$ production at all concentrations, especially at 0.0001 and $0.01 \mathrm{mg} / \mathrm{mL}$. After treatment with all doses of $A$. asarense bulbs extract, IFN- $\gamma$ production by lymphocytes was dropped, and this effect was remarkable at the lowest concentrations $(0.0001,0.001$ and $0.005 \mathrm{mg} / \mathrm{mL}$ ). The bulbs extract of $A$. asarense enhanced IL-4 production by the treated cells, whereas the bulbs extracts of $A$. sativum, A. jesdianum, and $A$. lenkoranicum had inhibitory effects on the production of IL-4. Treatment with the bulbs extracts of A. sativum and $A$. asarense caused increases in the secretion of IL-17 by the lymphocytes to some extent; however, the cytokine production decreased somewhat after incubation with $A$. jesdianum bulbs extracts. IFN- $\gamma /$ IL-4 ratio was raised after treatment of lymphocytes with $A$. stipitatum and $A$. sativum bulbs extracts, while incubation with $A$. asarense bulbs extracts decreased it.
\end{abstract}

Conclusion: Since the bulbs extracts of the studied Allium species demonstrated immunomodulatory features, with further research, they would be considered as useful candidate for clinical purposes.

\footnotetext{
* Corresponding Author:

Tayebeh Radjabian, $P h D$.

Address: Department of Biology, Faculty of Basic Sciences, Shahed University, Tehran, Iran

Phone: +98 (21) 66418216

E-mail: rajabian@shahed.ac.ir
} 


\section{Introduction}

$A$

llium L. belongs to the Alliaceae family [1, 2]. Iran is the main center of Allium species diversity in central and southwest Asia, with $\geq 115$ known species, including $>40$ endemic ones [3]. Allium sativum (garlic), as a prominent species of the genus, was cultivated for culinary practices and a therapeutic potency $[4,5]$ on account of its constituents, including sulfur compounds, enzymes, amino acids, lectins, and minerals [6, 7]. Garlic bulbs and their components were beneficial in combating various diseases in traditional medicine. For instance, in the Al-Qanoon Fi-al Tib (The Canon of Medicine) book, Avicenna wrote, garlic has been recommended for its potential therapeutic efficacies for arthritis, toothache, chronic cough, constipation, parasitic infestation, and infectious diseases [7, 8]. Currently, garlic's antimicrobial, antioxidant, anti-carcinogenic, and anti-inflammatory traits have attracted particular attention from modern medicine [2, 8-11]. The medicinal influences of garlic have been attributed to the presence of sulfur compounds, namely allicin, diallyl disulfide, S-allyl cysteine, and diallyl trisulfide $[12,13]$.

Cytokines secreted by various cells mediate immunoregulatory activities and the modulation of immune-related disorders, such as cancer, allergy, and autoimmune diseases $[14,15]$. Furthermore, they play critical roles in controlling immune responses through their specific receptors and activating cell signaling $[15,16]$. Due to their diverse activities, the modulation of cytokine secretion was a pharmacological target to manage the diseases. Despite administratng cytokines in the clinic, the primary concern for using these drugs is their side effects, e.g. transient lymphopenia or monocytopenia. Owing to the lower side effects, the administration of herbal medicines may be helpful for the regulation of cytokines [17]. Many scholars have reported garlic effects regarding the immunomodulatory features and bioactive constituents [9, 18-21]. Kang et al. [22] reported a considerable increase in TNF- $\alpha$ (Tumor Necrosis Factor- alpha) production by the treated macrophages at 10 and 100 $\mathrm{ng} / \mathrm{mL}$ of allicin.

Accordingly, there was a slight rise in IL-1 (Interlukine-1) and IL-6 (Interlukine-6) secretion by macrophages at $100 \mathrm{ng} / \mathrm{mL}$ of this metabolite. Clement et al [23] separated 3 proteins (QR-1, QR-2, \& QR-3) from $30 \mathrm{kDa}$ ultrafiltrate of raw garlic extract. The $3 \mathrm{immu}$ nomodulatory proteins had mitogenic effects on human peripheral blood lymphocytes, murine splenocytes, and thymocytes, especially QR-2. Despite several reports on the impacts of garlic extracts on immunity, Information about whether other Allium species have immunomodulatory features remains scarce. Considering that several domesticated and wild Allium species grow in Iran, there are no reports about their biological activities. Therefore, conducting some research on the immunomodulatory effects of their extracts seems to be necessary. In the present study, to introduce some new plant species with potent immunomodulatory features, in addition to garlic, the impact of some wild Allium species on T helper cell cytokines was investigated for the first time.

\section{Materials and Methods}

\section{Plant extract preparation}

Cultivated A. sativum bulbs were purchased from a field in Hamedan (Iran), and wild plants of A. lenkoranicum, A. jesdianum, A. asarense, and A. stipitatum were collected from their natural habitats from different regions of Iran. The Allium species were taxonomically identified by Dr. Shahin Zarre (School of Biology, College of Science, University of Tehran), and a voucher specimen of each plant species was deposited in the Central Herbarium of the University of Tehran (TUH) (Table 1).

The aqueous extracts of the bulbs were prepared using the method of Wang et al. [19] with a slight modification. The peeled bulbs (100 g) of each examined spe-

Table 1. The scientific names and geographical locations of the examined Allium species collection sites

\begin{tabular}{|c|c|c|c|c|c|}
\hline Allium Species & Collection Site & Latitude (N) & Longitude (E) & Altitude (m) & $\begin{array}{l}\text { Voucher } \\
\text { No. }\end{array}$ \\
\hline A. sativum $\mathrm{L}$. & A field in Hamedan province & $34 \div 47^{\prime}$ & $48030^{\prime}$ & 1737 & - \\
\hline A. asarense R.M. Fritsch \& Matin & Asara- Alborz Province & $36002^{\prime}$ & $51^{\circ} 11^{\prime}$ & 1896 & 35782 \\
\hline A. lenkoranicum Miscz. ex Grossh & $\begin{array}{l}25 \mathrm{~km} \text { from Khalkhal road to Asalem- } \\
\text { Ardebil Province }\end{array}$ & $37^{\circ}-38^{\prime}$ & $48^{\circ} 32^{\prime}$ & 1500 & 37322 \\
\hline A. jesdianum Boiss. \& Buhse & $\begin{array}{l}20 \mathrm{~km} \text { from Kandovan Village- East } \\
\text { Azerbaijan Province }\end{array}$ & $37047^{\prime}$ & $46014^{\prime}$ & 1950 & 35026 \\
\hline A. stipitatum Regel & Zagros mountain- Lorestan Province & $33 \circ 55^{\prime}$ & $48024^{\prime}$ & 2010 & 34799 \\
\hline
\end{tabular}


cies, after storage at $-20^{\circ} \mathrm{C}$ for 4-6 months, were crushed and homogenized with $100 \mathrm{~mL}$ of distilled water. Then, aqueous extracts were collected and added at different concentrations $(0-0.1 \mathrm{mg} / \mathrm{mL})$ to the culture media.

Animals

Six-to-eight-week-old male BALB/c mice were purchased from the Pasteur Institute of Iran (Tehran, Iran). They were kept under pathogen-free conditions.

\section{Isolation and culture of lymphocytes}

Lymphocytes were isolated from the mouse spleen using sterile needles and RPMI 1640 medium. After centrifugation, the cell suspension was washed with RPMI1640, and RBCs were excluded by Erythrocyte lysis buffer. The pellet was cultured into 96-well plates using RPMI 1640 containing 10\% Fasting Blood Sugar (FBS) in the presence of the different concentrations of the bulb extract of Allium species $(0-0.1 \mathrm{mg} / \mathrm{mL})$, except controls, at $37^{\circ} \mathrm{C}$ in a $5 \% \mathrm{CO}_{2}$ humidified incubator.

\section{Cytokines assay}

IFN- $\gamma$ (Interferon-gamma), IL-4 (Interlukine-4), and IL-17 (Interlukine-7) are representative of Th1 (T-helper 1), Th2, and Th17, respectively. Therefore, lymphocytes were treated with Allium bulbs extracts to determine their concentrations. Then, the supernatants were collected and stored at $-70{ }^{\circ} \mathrm{C}$, and the cytokine levels in the supernatants were assayed using an ELISA kit (R\&D Systems). All tests were performed according to the manufacturer's guidelines.
All statistical analyses were performed by SPSS. An index production for cytokines assessing for each sample was calculated as follows:

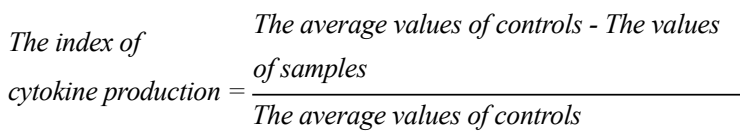

All tests were performed in triplicate, and the results were expressed as Mean \pm SE. One-way Analysis of Variance (ANOVA) was performed to determine statistically significant differences between mean scores. Tukey's multiple-comparison test was used to compare the group means, and significant differences were considered at $\mathrm{P} \leq 0.05$.

\section{Results}

\section{The levels of IFN-ץ production}

The cytokine level was assessed to evaluate the effect of aqueous bulbs extracts of five Allium species on IFN- $\gamma$ production by lymphocytes. As shown in Figure 1, all concentrations of $A$. sativum bulbs extract significantly increased the IFN- $\gamma$ level, especially at $0.0001-0.01 \mathrm{mg} /$ $\mathrm{mL}$. However, it was noticeable that the inhibitory effects of $A$. asarense bulbs extract at all concentrations (0.0001-0.1 mg/mL) were remarkable compared to $A$. sativum. Furthermore, the bulbs extract of $A$. stipitatum slightly suppressed IFN- $\gamma$ production. In contrast, those of $A$. jesdianum and A. lenkoranicum induced the IFN- $\gamma$ production by lymphocytes at different concentrations.

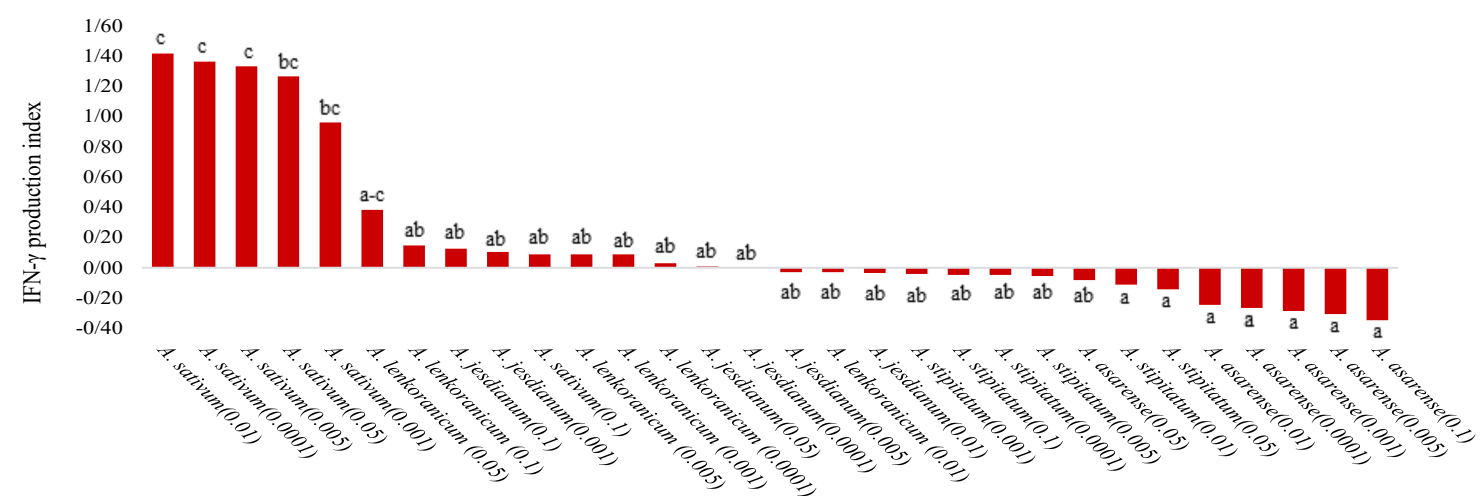

Species $(\mathrm{mg} / \mathrm{mL}$ of bulb extract)

Figure 1. The effects of aqueous bulb extracts of the examined Allium species on IFN- $\gamma$ production in lymphocytes Values followed by the same letter $(\mathrm{s})$ are not significantly different at $\mathrm{P}<0.05$ based on Tukey's multiple-comparison test. 


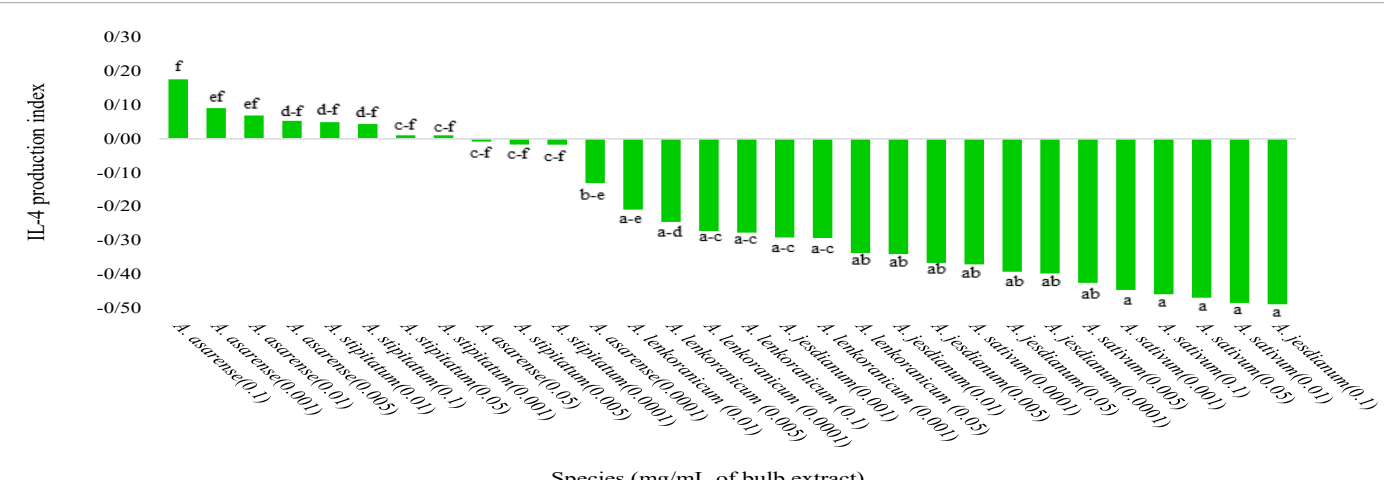

IminoRoRgulation

Figure 2. The effects of aqueous bulbs extracts of the examined Allium species on IL-4 secretion in lymphocytes Values followed by the same letter (s) are not significantly different at $\mathrm{P}<0.05$ based on Tukey's multiple-comparison test.

\section{The levels of IL-4 production}

Data analysis indicated the dose-dependent effects of the five studied Allium species on IL-4 production at some concentrations. As per Figure 2, the treatment with the bulbs extract of $A$. asarense raised IL-4 production in the lymphocytes at most of the applied doses, remarkably at $0.1 \mathrm{mg} / \mathrm{mL}$, although incubation at 0.0001 and $0.05 \mathrm{mg} / \mathrm{mL}$ led to a slight decrease in the IL-4 production. The bulbs extract of $A$. sativum and $A$. jesdianum at all used concentrations substantially dropped the production level compared to that of $A$. asarense. The suppressing effects of different concentrations of $A$. lenkoranicum bulbs extract, and the lowest dosages of $A$. stipitatum bulbs extract $(0.0001$ and $0.005 \mathrm{mg} / \mathrm{mL})$ on IL-4 production were insignificant. At other concentra- tions $(0.001-0.1 \mathrm{mg} / \mathrm{mL})$, A. stipitatum bulbs extract stimulated lymphocyte marginally for producing IL-4.

\section{The levels of IL-17 production}

The cytokine assays demonstrated a similar impact of $A$. sativum and $A$. asarense bulbs extracts in the regulation of IL-17 production. Thus, the incubation with bulbs extracts of both species caused insignificant increases in the levels of this cytokine in lymphocytes at all applied concentrations, except for $0.1 \mathrm{mg} / \mathrm{mL}$ of $A$. asarense extract. Moreover, compared to other species, the secretion of IL-17 by lymphocytes was decreased gradually in a dose-independent manner after treatment with bulbs extract of $A$. jesdianum. Moreover, the lowest inhibitory and stimulatory effects on IL-17 production were ob-

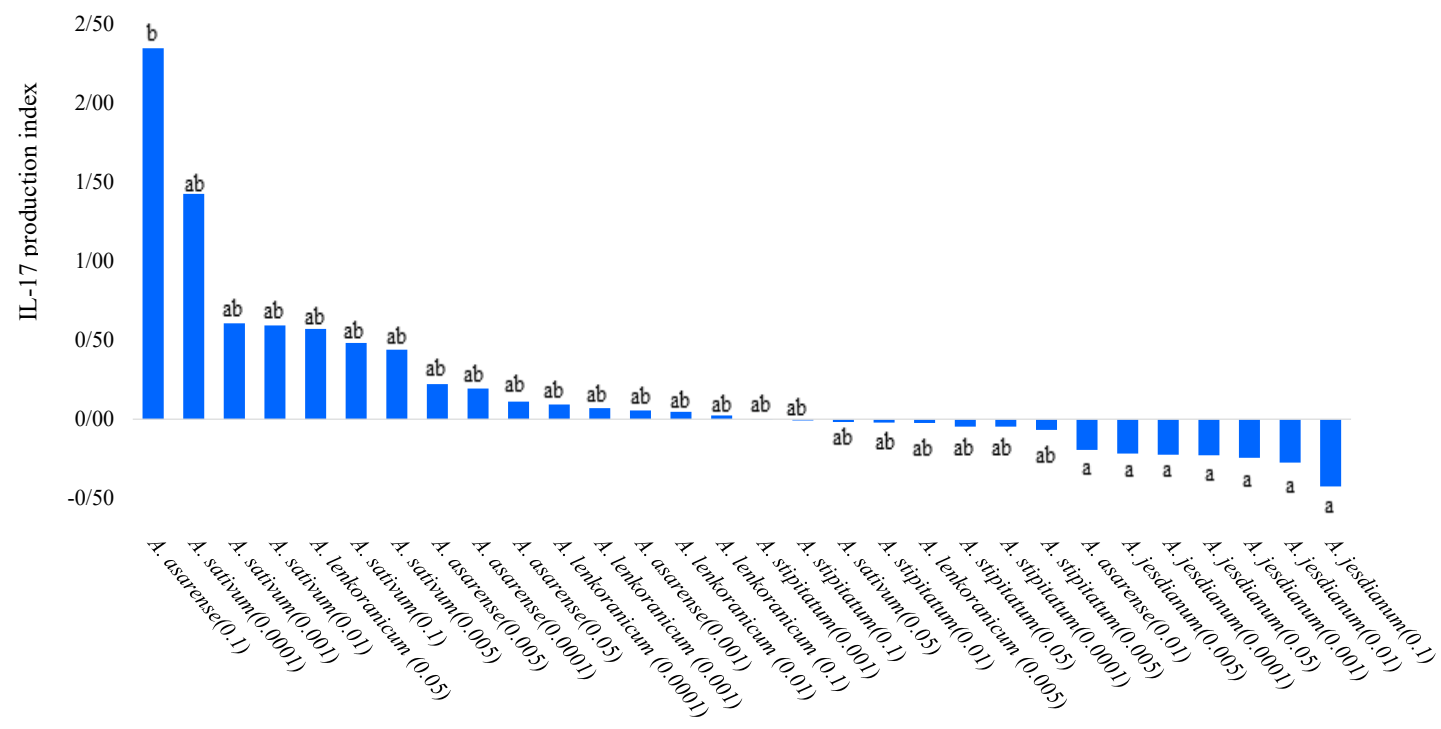

Species $(\mathrm{mg} / \mathrm{mL}$ of bulb extract)

Figure 3. The effects of aqueous bulb extracts of the examined Allium species on IL-17 production in lymphocytes 


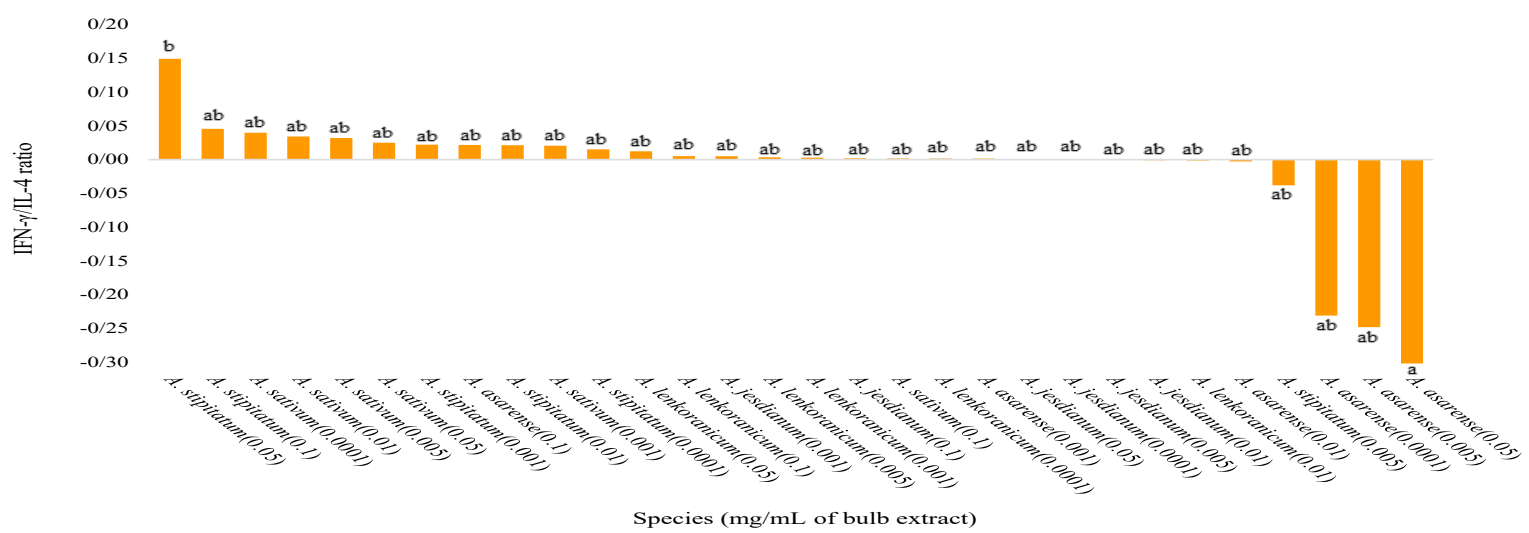

Figure 4. The effects of aqueous bulb extracts of the examined Allium species on the IFN- $\gamma /$ IL-4 ratio

IMMUNoRegLLATION

Values followed by the same letter (s) are not significantly different at $\mathrm{P}<0.05$ based on Tukey's multiple-comparison test.

served after treatment of the lymphocytes with different concentrations of the bulbs extracts of $A$. stipitatum and A. lenkoranicum, respectively (Figure 3 ).

\section{The impact of the extracts on the IFN- $/ / \mathrm{IL}-4$ ratio}

The impacts of studied Allium species on the IFN- $\gamma$ / IL-4 ratio were assessed. The ratio was considered representative of $\mathrm{Th} 1 / \mathrm{Th} 2$. According to the results presented in Figure 4, A. stipitatum bulb extract dramatically increased the IFN- $\gamma / \mathrm{IL}-4$ ratio at $0.05 \mathrm{mg} / \mathrm{mL}$, whereas the effect of other concentrations was insignificant. Additionally, slight increases in the IFN- $\gamma / \mathrm{IL}-4$ ratio were attained after treatment of lymphocytes with different concentrations of $A$. sativum bulbs extract, except at 0.1 $\mathrm{mg} / \mathrm{mL}$. Conversely, incubating the lymphocytes with bulbs extract of $A$. asarense at $0.05 \mathrm{mg} / \mathrm{mL}$ significantly decreased the IFN- $\gamma / \mathrm{IL}-4$ ratio. However, at 0.0001 and $0.005 \mathrm{mg} / \mathrm{mL}$, the extract caused a moderate drop in the cytokines ratio. Besides, these decreases were inconsiderable at other applied concentrations. The different concentrations of $A$. jesdianum and A. lenkoranicum bulbs extracts had no statistically significant effect, neither stimulatory nor inhibitory, on the IFN- $\gamma / \mathrm{IL}-4$ ratio.

\section{Discussion}

Several published reports exist about the beneficial effects of garlic and onion crude extracts or their components on the immune system. However, there is inadequate evidence for the impacts of extracts of other members of Allium species in the literature. Therefore, the current study evaluated the effects of bulbs extract of some Allium species on the cells cytokine profiles. The treatment of lymphocytes with the bulbs extracts of selected Allium species exhibited that A. sativum extract enhanced IFN- $\gamma$ production at all doses, especially at 0.0001 and $0.01 \mathrm{mg} / \mathrm{mL}$ concentrations. However, all doses of $A$. asarense bulbs extract diminished the IFN- $\gamma$ level in the lymphocytes, and this effect was remarkable at the lowest concentrations $(0.0001,0.001$, and 0.005 $\mathrm{mg} / \mathrm{mL})$. In the case of IL-4, $A$. asarense bulbs extract increased this cytokine production by the treated cells; however, A. sativum, A. jesdianum, and A. lenkoranicum bulbs extract reduced IL-4 level, especially $A$. sativum at the higher concentrations $(0.01$ and $0.05 \mathrm{mg} /$ $\mathrm{mL}$ ). After cell treatment with A. sativum and A. asarense bulbs extracts, an insignificant increase was found in the level of IL-17, while A. jesdianum bulbs extract slightly decreased cytokine production. Our findings are in line with the results of some similar reports on the effects of garlic extract on the immunity system. Ghazanfari et al. [24] reported the therapeutic impacts of garlic extract and glucantime on Leishmania primary infected $\mathrm{BALB} / \mathrm{c}$ mice. Their findings indicated that the secretion of Th1-type cytokines (IFN- $\gamma$ and IL-2) was stimulated after garlic treatment, and the levels of Th2-type cytokines (IL-4 and IL-1) were suppressed, demonstrating Th1-type responses.

Moreover, Larypoor et al. [25] assessed the immunomodulatory effects of Aged Garlic Extract (AGE) and aflatoxin B1. A significant increase in the production patterns of IFN- $\gamma$, as well as Th1, was detected in the AGE-treated mice, while aflatoxin B1 reduced IL-4 production. In the current study, in non-pathological conditions, inoculation with $A$. sativum bulb extract stimulated IFN- $\gamma$ production and inhibited the secretion of IL- 4 by lymphocytes. Furthermore, compared to A. sativum, the bulbs extract of $A$. asarense decreased IFN- $\gamma$ levels, while it had an increasing impact on IL-4 production. In research conducted by Shamlou et al. [26], the injected hydroalcoholic bulb extract of $A$. hirtifolium (shallot) plummeted IL-4 secretion by BALB/c mice 
lymphocytes at $400 \mathrm{mg} / \mathrm{kg}$ dose. In another study, after $24 \mathrm{~h}$ of the incubation of murine thymocytes with $A$. cepa (onion) agglutinin, high levels of IL-2 and IFN- $\gamma$ with negligible effect on IL-4 level were detectable. Besides, in the mentioned research, the stimulatory effects of this lectin were higher at $0.01 \mu \mathrm{g} /$ well, as a lower dose, than those of $10 \mu \mathrm{g} /$ well, as a higher dose [27]. Here, the bulbs extract of $A$. sativum and A. jesdianum reduced the IL-4 produced by lymphocytes in a dose-independent manner. The bulbs extract of $A$. lenkoranicum also had a moderating effect on the decline of IL-4 levels at all concentrations. Contrary to our results, Zamani et al. [28] reported that the intake of garlic by rats caused increases in the IL-4 levels and stimulated Th2 responses; however, the production of IFN- $\gamma$ decreased considerably. In other words, they suggested that administrating garlic could switch on Th2 responses. Peyer's patch cell treated orally with garlic extract led to a substantial rise in the IFN- $\gamma$ and IL-4 levels [29]. Based on our findings, different concentrations of bulb extract of $A$. asarense increased IL-4 levels.

Moutia et al. [30] assessed the effects of various doses of garlic extract on cytokine production by human Peripheral Blood Mononuclear Cells (PBMCs). They reported that producing IL-17 and its gene expression was significantly enhanced in PBMCs after treatment with garlic; however, the gene expression level of IL-4 was unchanged. A similar result of the present research indicated that treatment with $A$. sativum and $A$. asarense bulbs extracts was conducted to Th17 cytokine profile in protein level. However, the incubation of lymphocytes with $A$. jesdianum bulb extract resulted in a marginal decrease in IL-17 production. Interestingly, in the report of Moutia et al. [30], garlic extract suppressed IL-17 gene expression in the stimulated PBMCs with PHA as a mitogen. Another research reported a synergistic anti-inflammatory effect after co-treatment with $A$. hookeri and Curcuma longa extracts (3:7) in an air pouch model. The levels of IFN- $\gamma$, IL-1 $\beta$, IL-6, IL-13, and IL-17 declined after co-treatment with the extracts; although $500 \mathrm{mg} / \mathrm{kg}$ co-treatment consisted $350 \mathrm{mg} / \mathrm{kg} \mathrm{A}$. hookeri extract had a suppressor impact on IFN- $\gamma$ and TNF- $\alpha$ secretion [31].

Similarly, in our work, treatments with $A$. asarense and A. jesdianum bulbs extract suppressed IFN- $\gamma$ and IL-17 production, respectively, as inflammatory cytokines. Shirgholami et al. [32] reported substantial increases in the IFN- $\gamma$ levels in serum of infected BALB/c mice with cystic echinococcosis after administrating $20 \mathrm{mg} /$ $\mathrm{kg}$ and $80 \mathrm{mg} / \mathrm{kg}$ methanolic extract of $A$. sativum. Several factors may influence the production of cytokines in the treated lymphocytes with extracts of Allium species.
They might include normal or pathologic conditions in the study, the type of administrated species and their various preparations, the concentrations of used extract, and in vitro or in vivo studies.

The IFN- $\gamma / \mathrm{IL}-4$ ratio represents the ratio of Th1/Th2 in lymphocytes. This project detected the highest stimulatory effects on the IFN- $\gamma / \mathrm{IL}-4$ ratio in the lymphocytes after treatments with $A$. stipitatum $(0.05 \mathrm{mg} / \mathrm{mL})$ and $A$. sativum bulbs extracts. The incubation of lymphocytes with bulbs extract of $A$. asarense caused a decrease in the ratios of these cytokines. In a study designed by Liu and co-workers [33], adminstrating garlic oil to mice at 100 $\mathrm{mg} / \mathrm{kg}$ revealed an increase in IL- 2 and IFN- $\gamma$ levels, followed by a marginal decrease at $200 \mathrm{mg} / \mathrm{kg}$. IL-4 and IL10 production increased dramatically at the same doses, especially $200 \mathrm{mg} / \mathrm{kg}$. The maximum ratio of IFN- $\gamma / \mathrm{IL}-4$ was achieved at the dose of $50 \mathrm{mg} / \mathrm{kg}$, and after that, the ratio experienced a decline at $100 \mathrm{mg} / \mathrm{kg}$ and $200 \mathrm{mg} /$ $\mathrm{kg}$ doses. They concluded that garlic oil is involved in Th1 polarization at the lower doses; however, it could induce Th2 responses at the higher doses. Shamluo et al. [26] indicated that the extract of shallot suppressed Th1 and Th2 responses and their cytokines produced by lymphocytes. Here, the bulbs extracts of $A$. stipitatum and $A$. sativum regulated the immune system toward Th1 responses. Still, incubation with the bulbs extract of $A$. asarense dominantly led to Th2 response, especially at the lower concentrations. The studied species and their components and the used doses seemed to have had various effects on IFN- $\gamma / \mathrm{IL}-4$ ratios.

Since cytokines are secreted in response to pathological conditions, regulating their levels is more likely to be a therapeutic strategy in immune-associated disorders, such as cancer, asthma, and autoimmunity. Furtehermore, aged garlic extract had anti-cancer activity in mice by stimulating natural killer cells to secrete IFN- $\gamma$, IL-2, and TNF- $\alpha$ [34]. Moreover, the intra-peritoneal injection of black garlic extract boosted NK activity and the generation of IFN- $\gamma$, IL-2, and TNF- $\alpha$ secretion from Th1cells, whereas IL-4 production was suppressed by $\mathrm{T}$ helper type 2 cells [35]. Following the increasing impacts of $A$. stipitatum and $A$. sativum bulb extracts on IFN- $\gamma /$ IL-4 ratio and enhancing Th1 responses in our attempt, the effect of two species on the animal models of cancers can be assessed. There are pieces of evidence to support that tissue specific and systemic autoimmune diseases are the consequences of IFN- $\gamma$ overexpression. Multiple Sclerosis (MS), Systemic Lupus Erythematosus (SLE), Rheumatoid Arthritis (RA), and Type1 Diabetes (T1D) are examples of autoimmune diseases in which IFN- $\gamma$ and Th1 cells have a substantial role [36]. Regard- 
ing the obtained results, treatment with bulbs extract of $A$. asarense, especially at the lower doses, decreased IFN- $\gamma$ production in the lymphocytes; IFN- $\gamma /$ IL-4 ratios were also declined. The impacts of the extracts should be examined to determine whether they would relieve the mentioned autoimmune diseases in animal models or not. The secretion of IL-17 by Th17 participates in various inflammatory diseases, such as MS, RA, and Inflammatory Bowel Diseases (IBDs). Based on the findings of Hodge et al. [37], garlic extract at $\geq 10 \mu \mathrm{g} / \mathrm{mL}$ diminished the production of TNF- $\alpha$, IL- $1 \alpha$, IL- 6 , and IL- 8 by monocytes and the secretion of IFN- $\gamma$, IL- 2 , and TNF- $\alpha$ by T cells isolated from patients with IBD. IL-17, as an inflammatory cytokine, plays an essential role in the indication of IBD; thus, treatment with bulbs extract of $A$. jesdianum is more prone to be an appropriate option to investigate its effects on the animal model of IBD.

In the case of allergic diseases, the effects of intraperitoneal injections of aged garlic extract were assessed by Zare et al. [38] in a murine model of allergic airway inflammation. Their results indicated that three-time intraperitoneal injections of the extract led to significant decreases in the signs of allergy, including the percentage of eosinophil in lavage, IgG1 levels in the serum and lavage, the number of mucus-producing goblet cells in the airways, and perivascular inflammation. Additionally, based on their suggestion, an isolated $14 \mathrm{kDa}$ glycoprotein from extract had a crucial role in $\mathrm{T}$ helper-1 responses and immunomodulatory effects of garlic extract. Since the bulbs extracts of $A$. sativum, A. jesdianum, and A. lenkoranicum played inhibitory functions in the production of IL-4, the impacts of the bulbs extracts of these three species can reduce or delay inflammatory reactions in allergic diseases. However, further investigations are required in this respect.

\section{Conclusion}

This investigation evaluated the possible immunoregulatory effects of bulbs extracts of some selected Allium species. Besides $A$. sativum, the bulbs extracts of other examined Allium species showed stimulatory or suppressive effects on IFN- $\gamma$, IL-4, and IL-17 production under normal conditions. Interestingly, $A$. asarense bulbs extract inhibited IFN- $\gamma$ production while stimulated IL-4 production. The bulbs extract of $A$. jesdianum also suppressed IL-17 production; however, $A$. sativum and $A$. asarense extracts stimulated this cytokine production. Therefore, the extracts of $A$. asarense and $A$. jesdianum are considered potential anti-inflammatory responses. Our findings revealed that different concentrations of $A$. sativum bulb extract enhanced IFN- $\gamma /$ IL-4 ratios, while $A$. asarense bulbs extract had suppressive effects on IFN- $\gamma$ production by lymphocytes. Thus, the immunoregulatory features of Allium species look promising in clinical applications, and more studies are needed to identify their therapeutic roles on immune-related diseases.

\section{Ethical Considerations}

\section{Compliance with ethical guidelines}

The research was approved by the Ethics Committee of the Research Ethics Board of Shahed University (Code: 1394.103).

\section{Funding}

The Immunoregulation Research Center of Shahed University and Iran National Science Foundation (INSF) carried out the current study. Immunoregulation Research Center of Shahed University and Iran National Science Foundation has financially supported this paper.

\section{Authors' contributions}

Conceptualization, methodology, resources: All authors; Investigation: Tayebeh Radjabian, Zahra Hosseinpur Yektaei, Tooba Ghazanfari; Writing original draft: Tayebeh Radjabian, Zahra Hosseinpur Yektaei; Writing, review, and editing: Tayebeh Radjabian, Zahra Hosseinpur Yektaei, Tooba Ghazanfari; and Supervision: Tayebeh Radjabian.

\section{Conflicts of interest}

The authors declared no conflict of interests.

\section{Acknowledgements}

The authors would like to express their gratitude to the Immunoregulation Research Center of Shahed University for the financial supports during the course of this research.

\section{References}

[1] Aryakia E, Karimi HR, Naghavi MR, Shahzadeh Fazeli SA. Morphological characterization of intra-and interspecific diversity in some Iranian wild Allium species. Euphytica. 2016; 211(2):185-200. [DOI:10.1007/s10681-016-1729-8]

[2] Londhe V, Gavasane AT, NipateSS, Bandawane DD, Chaudhari PD. Role of garlic (Allium sativum) in various diseases: An overview. Journal of Pharmaceutical Research and Opinion. 2011; 12-3. https://www.researchgate.net/.pdf 
[3] Neshati F, Fritsch RM. Seed characters and testa sculptures of some Iranian Allium L. species (Alliaceae). Feddes Repertorium. 2009; 120(5-6):322-32. [DOI:10.1002/fedr.200911112]

[4] Suleria HAR, Butt MS, Khalid N, Sultan S, Raza A, Aleem $\mathrm{M}$, et al. Garlic (Allium sativum): Diet based therapy of 21st century-A review. Asian Pacific Journal of Tropical Disease. 2015; 5(4):271-8. [DOI:10.1016/S2222-1808(14)60782-9]

[5] Mellado-García P, Maisanaba S, Puerto M, Prieto AI, Marcos R, Pichardo S, et al. In vitro toxicological assessment of an organosulfur compound from Allium extract: Cytotoxicity, mutagenicity and genotoxicity studies. Food and Chemical Toxicology. 2017; 99:231-40. [DOI:10.1016/j.fct.2016.12.007] [PMID]

[6] Rana S, Pal R, Vaiphei K, Sharma SK, Ola R. Garlic in health and disease. Nutrition Research Reviews. 2011; 24(1):60-71. [DOI:10.1017/S0954422410000338] [PMID]

[7] Gebreyohannes G, Gebreyohannes M. Medicinal values of garlic: A review. International Journal of Medicine and Medical Sciences. 2013; 5(9):401-8. https://academicjournals.org/journal/IJMMS/article-abstract/4438B2713

[8] Bayan L, Koulivand PH, Gorji A. Garlic: A review of potential therapeutic effects. Avicenna Journal of Phytomedicine. 2014; 4(1):1-14. [PMID] [PMCID]

[9] Iciek M, Kwiecień I, Włodek L. Biological properties of garlic and garlic-derived organosulfur compounds. Environmental and Molecular Mutagenesis. 2009; 50(3):247-65. [DOI:10.1002/em.20474] [PMID]

[10] Capasso A. Antioxidant action and therapeutic efficacy of Allium sativum L. Molecules. 2013; 18(1):690-700. [DOI:10.3390/molecules18010690] [PMID] [PMCID]

[11] Putnik P, Gabrić D, Roohinejad S, Barba FJ, Granato D, Mallikarjunan $\mathrm{K}$, et al. An overview of organosulfur compounds from Allium spp: From processing and preservation to evaluation of their bioavailability, antimicrobial, and antiinflammatory properties. Food Chemistry. 2019; 276:680-91. [DOI:10.1016/j.foodchem.2018.10.068] [PMID]

[12] Upadhyay RK. Nutritional and therapeutic potential of Allium vegetables. Journal of Nutrition Therapeutics. 2017; 6(1):18-37. [DOI:10.6000/1929-5634.2017.06.01.3]

[13] Singh R, Singh K. Garlic: A spice with wide medicinal actions. Journal of Pharmacognosy and Phytochemistry. 2019; 8(1):1349-55. https:/ / www.phytojournal.com/archives?yea $\mathrm{r}=2019$ \&vol $=8$ \&issue $=1 \&$ ArticleId $=6946$

[14] O'Shea JJ, Ma A, Lipsky P. Cytokines and autoimmunity. Nature Reviews Immunology. 2002; 2(1):37-45. [DOI:10.1038/nri702] [PMID]

[15] Tsuchida Y, Fujio K. Cytokines and chemokines. In: Perricone C, Shoenfeld Y, editors. Mosaic of Autoimmunity: The Novel Factors of Autoimmune Diseases. London: Academic Press; 2019. p. 127-41. [DOI:10.1016/B978-0-12-814307-0.00015-3]

[16] Silk AW, Margolin K. Cytokine therapy. Hematology/ Oncology Clinics of North America. 2019; 33(2):261-74. [DOI:10.1016/j.hoc.2018.12.004] [PMID]

[17] Spelman K, Burns J, Nichols D, Winters N, Ottersberg S, Tenborg M. Modulation of cytokine expression by traditional medicines: A review of herbal immunomodulators. Alternative Medicine Review. 2006; 11(2):128-50. [PMID]
[18] Bhattacharyya M, Girish G, Karmohapatra SK, Samad S, Sinha AK. Systemic production of IFN-a by garlic (Allium sativum) in humans. Journal of Interferon \& Cytokine Research. 2007; 27(5):377-82. [DOI:10.1089/jir.2006.0124] [PMID]

[19] Wang X, Jiao F, Wang QW, Wang J, Yang K, Hu RR, et al. Aged black garlic extract induces inhibition of gastric cancer cell growth in vitro and in vivo. Molecular Medicine Reports. 2012; 5(1):66-72. [DOI:10.3892/mmr.2011.588]

[20] Kim MJ, Yoo YC, Kim HJ, Shin SK, Sohn EJ, Min AY, et al. Aged black garlic exerts anti-inflammatory effects by decreasing no and proinflammatory cytokine production with less cytoxicity in LPS-stimulated raw 264.7 macrophages and LPS-induced septicemia mice. Journal of Medicinal Food. 2014; 17(10):1057-63. [DOI:10.1089/jmf.2013.3043] [PMID]

[21] Sultan MT, Buttxs MS, Nasir Qayyum MM, Rasul Suleria HA. Immunity: plants as effective mediators. Critical Reviews in Food Science and Nutrition. 2014; 54(10):1298-308. [DOI:10.1080/10408398.2011.633249] [PMID]

[22] Kang N, Moon E, Cho C, Pyo S. Immunomodulating effect of garlic component, allicin, on murine peritoneal macrophages. Nutrition Research. 2001; 21(4):617-26. [DOI:10.1016/S0271-5317(01)00269-X]

[23] Clement F, Pramod SN, Venkatesh YP. Identity of the immunomodulatory proteins from garlic (Allium sativum) with the major garlic lectins or agglutinins. International Immunopharmacology. 2010; 10(3):316-24. [DOI:10.1016/j. intimp.2009.12.002] [PMID]

[24] Ghazanfari T, Hassan Z, Ebtekar M, Ahmadiani A, Naderi G, Azar A. Garlic induces a shift in cytokine pattern in Leishmania major-infected Balb/c mice. Scandinavian Journal of Immunology. 2000; 52(5):491-5. [DOI:10.1046/j.13653083.2000.00803.x] [PMID]

[25] Larypoor M, Bayat M, Zuhair MH, Akhavan Sepahy A, Amanlou M. Evaluation of the number of CD4+ CD25+ FoxP3+ Treg cells in normal mice exposed to AFB1 and treated with aged garlic extract. Cell Journal. 2013;15(1):37-44 [PMID] [PMCID]

[26] Shamlou S, Gorgin Karaji A, Hasanpoor Z, Askari V, Mostafaie A. The effect of shallot (Allium hirtifolium) extract on profile of Th1/Th2 cytokines in Balb/C mouse splenic lymphocytes. Journal of Reports in Pharmaceutical Sciences. 2016; 5(2):61-6. https://www.jrpsjournal.com/article. asp?issn $=2322-1232 ; 61 ;$ epage $=66$; aulast $=$ Shamlou; type $=0$

[27] Prasanna VK, Venkatesh YP. Characterization of onion lectin (Allium cepa agglutinin) as an immunomodulatory protein inducing Th1-type immune response in vitro. International Immunopharmacology. 2015; 26(2):304-13. [DOI:10.1016/j.intimp.2015.04.009] [PMID]

[28] Zamani A, Vahidinia A, Sabouri Ghannad M. The effect of garlic consumption on Th1/Th2 cytokines in phytohemagglutinin (PHA) activated rat spleen lymphocytes. Phytotherapy Research. 2009; 23(4):579-81. [DOI:10.1002/ptr.2700] [PMID]

[29] Ota N, Takano F, Muroga S, Kawabata T, Ishigaki Y, Yahagi N, et al. Garlic extract and its selected organosulphur constituents promote ileal immune responses ex vivo. Journal of Functional Foods. 2012; 4(1):243-52. [DOI:10.1016/j. jff.2011.11.003]

[30] Moutia M, Seghrouchni F, Abouelazz O, Elouaddari A, Al Jahid A, Elhou A, et al. Allium sativum L. regulates in vitro 
IL-17 gene expression in human peripheral blood mononuclear cells. BMC Complementary and Alternative Medicine. 2016; 16(1):377. [DOI:10.1186/s12906-016-1365-9] [PMID] [PMCID]

[31] Lee SY, Cho SS, Li Y, Bae CS, Park KM, Park DH. Antiinflammatory effect of Curcuma longa and Allium hookeri co-treatment via NF-kB and COX-2 pathways. Scientific Reports. 2020; 10(1):5718. [DOI:10.1038/s41598-020-62749-7] [PMID] [PMCID]

[32] Shirgholami Z, Borji H, Mohebalian H, Heidarpour M. Effects of Allium sativum on IFN- $\gamma$ and IL4 concentrations in mice with cystic echinococcosis. Experimental Parasitology. 2021; 220:108042. [DOI:10.1016/j.exppara.2020.108042] [PMID]

[33] Liu CT, Su HM, Lii CK, Sheen LY. Effect of supplementation with garlic oil on activity of Th1 and Th2 lymphocytes from rats. Planta Medica. 2009; 75(03):205-10. [DOI:10.1055/s-0028-1088396] [PMID]

[34] Kyo E, Uda N, Suzuki A, Kakimoto M, Ushijima M, Kasuga $S$, et al. Immunomodulation and antitumor activities of aged garlic extract. Phytomedicine. 1998; 5(4):259-67. [DOI:10.1016/S0944-7113(98)80064-0]

[35] Wang D, Feng Y, Liu J, Yan J, Wang M, Sasaki JI, et al. Black garlic (Allium satioum) extracts enhance the immune system. Medicinal and Aromatic Plant Science and Biotechnology. 2010; 4(1):37-40. https:/ / zenian.co.nz/wp-content/ uploads/2014/05/Japanese-+--on-black-garlic.pdf

[36] Lees JR. Interferon gamma in autoimmunity: A complicated player on a complex stage. Cytokine. 2015; 74(1):18-26. [DOI:10.1016/j.cyto.2014.10.014] [PMID]

[37] Hodge G, Hodge S, Han P. Allium sativum (garlic) suppresses leukocyte inflammatory cytokine production in vitro: potential therapeutic use in the treatment of inflammatory bowel disease. Cytometry. 2002; 48(4):209-15. [DOI:10.1002/ cyto.10133] [PMID]

[38] Zare A, Farzaneh P, Pourpak Z, Zahedi F, MoinShahabi S. Purified aged garlic extract modulates allergic airway inflammation in BALB/c mice. Iranian Journal of Allergy, Asthma and Immunology. 2008; 7(3):133-41. [PMID] 
This Page Intentionally Left Blank 